\title{
К ВОПРОСУ ПРИМЕНЕНИЯ ВІМ-ТЕХНОЛОГИИ ДЛЯ СОЗДАНИЯ БИБЛИОТЕКИ 3D-ОБЪЕКТОВ КУЛЬТУРНО-ИСТОРИЧЕСКОГО НАСЛЕДИЯ
}

\section{Татьяна Викторовна Иванова}

Сибирский государственный университет геосистем и технологий, 630108, Россия, г. Новосибирск, ул. Плахотного, 10, обучающийся, тел. (383)361-01-09, e-mail: tatyanka-TANYA-ivanova@mail.ru

\section{Максим Александрович Малиновский}

Сибирский государственный университет геосистем и технологий, 630108, Россия, г. Новосибирск, ул. Плахотного, 10, ассистент кафедры кадастра и территориального планирования, тел. (383)361-01-09, e-mail: mk26@ngs.ru

Когда здание больше не существует и его место используется по другому назначению, то физическая реконструкция больше не имеет смысла. Однако виртуальная реконструкция может помочь вернуть жизнь зданию. В статье рассмотрена цифровая реконструкция кинотеатра «Металлист» в Новосибирске, построенный в 1934 году, практически разрушенное в результате ряда нормативно-правовых коллизий.

Ключевые слова: BIM, 3D-моделирование, виртуальная реконструкция

\section{ON THE ISSUE OF USING BIM-TECHNOLOGY TO CREATE A LIBRARY OF 3D-OBJECTS OF CULTURAL AND HISTORICAL HERITAGE}

\section{Tatyana V. Ivanova}

Siberian State University of Geosystems and Technologies, 10, Plakhotnogo St., Novosibirsk, 630108, Russia, Student, phone: (383)361-01-09, e-mail: tatyanka-TANYA-ivanova@mail.ru

\section{Maxim A. Malinovsky}

Siberian State University of Geosystems and Technologies, 10, Plakhotnogo St., Novosibirsk, 630108, Russia, Student, phone: (383)361-01-09, e-mail: mk26@ngs.ru

When a building no longer exists and its place is used for a different purpose, then physical reconstruction no longer makes sense. However, virtual reconstruction can help restore life to a building. The article discusses the digital reconstruction of the Metalist cinema in Novosibirsk, built in 1934, which was almost destroyed as a result of a number of regulatory conflicts.

Key words: BIM, 3D-modeling, virtual reconstruction

В Новосибирске, как в любом современном быстроразвивающимся мегаполисе с богатой исторической основой вопрос сохранения и репрезентации объектов культурно-исторического наследия приобрел особую актуальность. В сформировавшихся условиях коммерциализации общества памятники архитектуры стремительно исчезают под напором «цивилизованных» бизнесменов, которым скорее и дешевле демонтировать устаревший объект и на освободившемся земельном участке возвести очередную новостройку, чем реставрировать, возрождать и изыскивать методы их интеграции в полноценную экономическую жизнь региона. Это 
особо ценный фонд городов, который при грамотном использовании может приносить доход и существенно влиять на экономическое развитие территории.

Реставрационно-проектная деятельность - сфера, которую минимально затронули современные технологии информационного моделирования объектов капитального строительства (BIM). И хотя значимость специализированного программного обеспечения в комплексе с технологией наземного и воздушного лазерного сканирования для создания 3D моделей объектов (рис. 1), а также повышения эффективности научных исследований и анализа памятников архитектуры не вызывает сомнений, в силу специфики решаемых задач компьютерные технологии еще мало применяются непосредственно в создании проектов реконструкции, и в большей степени направленны на создание новых зданий и сооружений.

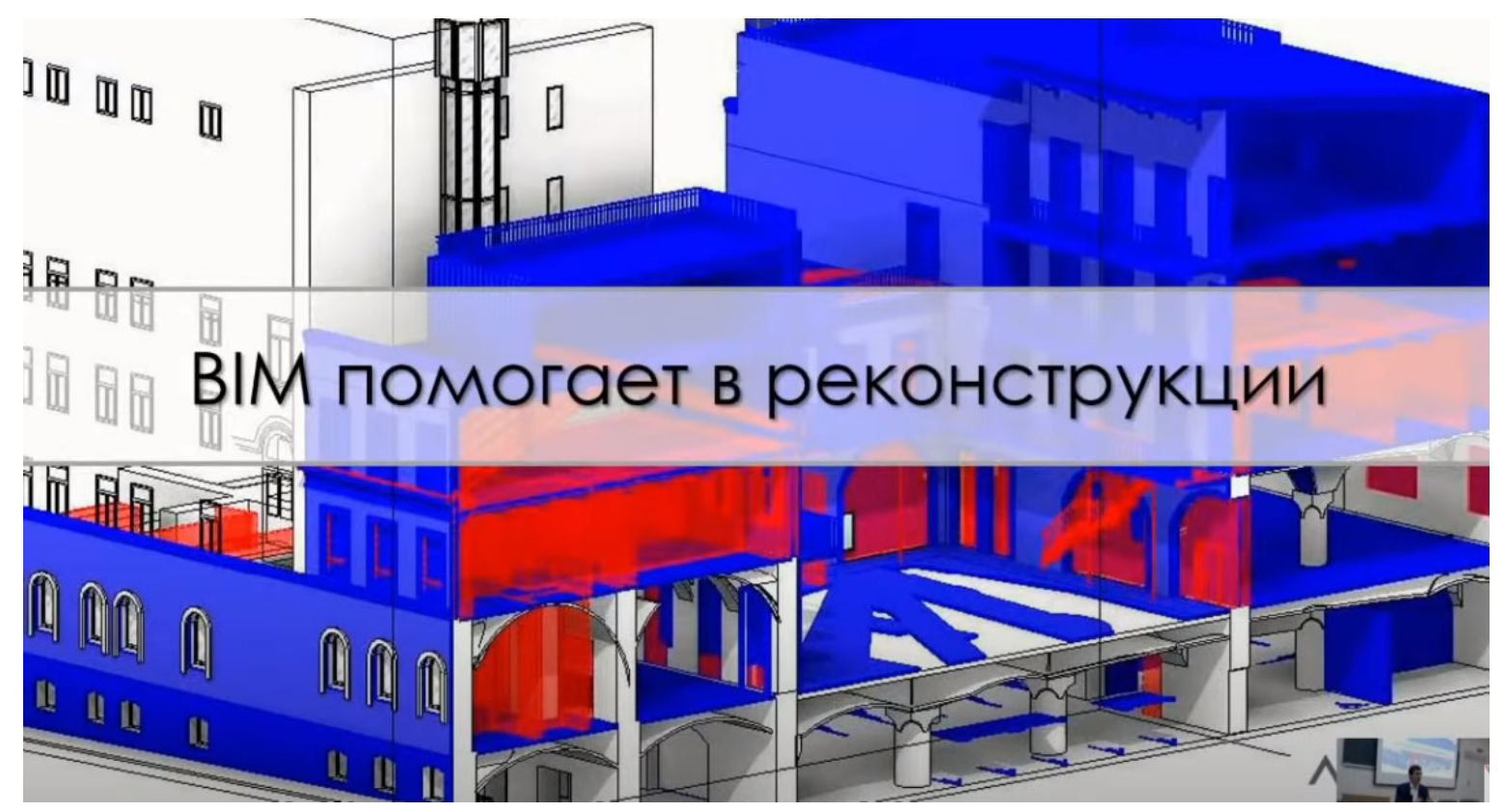

Рис. 1. Торговый дом Камилла Депре

По определению ВІМ-моделирование предполагают инновационный подход к проектированию, возведению, оснащению и ремонту объектов недвижимости. При этом создаваемая модель тесно связана с базами данных, где каждому ее элементу присваиваются необходимые аттрибуты. Более того, не будет преувеличением сказать, что ВIM-технологии раскрывают поистине уникальные возможности в области реставрационно-проектной деятельности. Конечно, такого рода работа требует высококвалифицированных исполнителей в области BIM, но наш опыт показал, что любой желающий, может подняться до этого уровня, если захочет.

Информационное моделирование недвижимых объектов культурного наследия можно упрощенно охарактеризовать как новый подход к вопросу фиксации памятников. Хотя на самом деле ВIM здесь даёт намного больше. 
По сути, информационная модель становится местом и средством не только хранения информации об объекте, но и серьезным инструментом исследовательской работы с этой информацией, а также в учебной и коммуникативной деятельности. Эта модель также тесно связана с мониторингом состояния объекта и его возможного использования (эксплуатации) [1]. Таким образом, информационная модель архитектуры является не просто ее виртуальной копией, а "интеллектуальным контейнером" с взаимосвязанной информацией об объекте, причем объем этого контейнера практически неограничен (рис. 2).

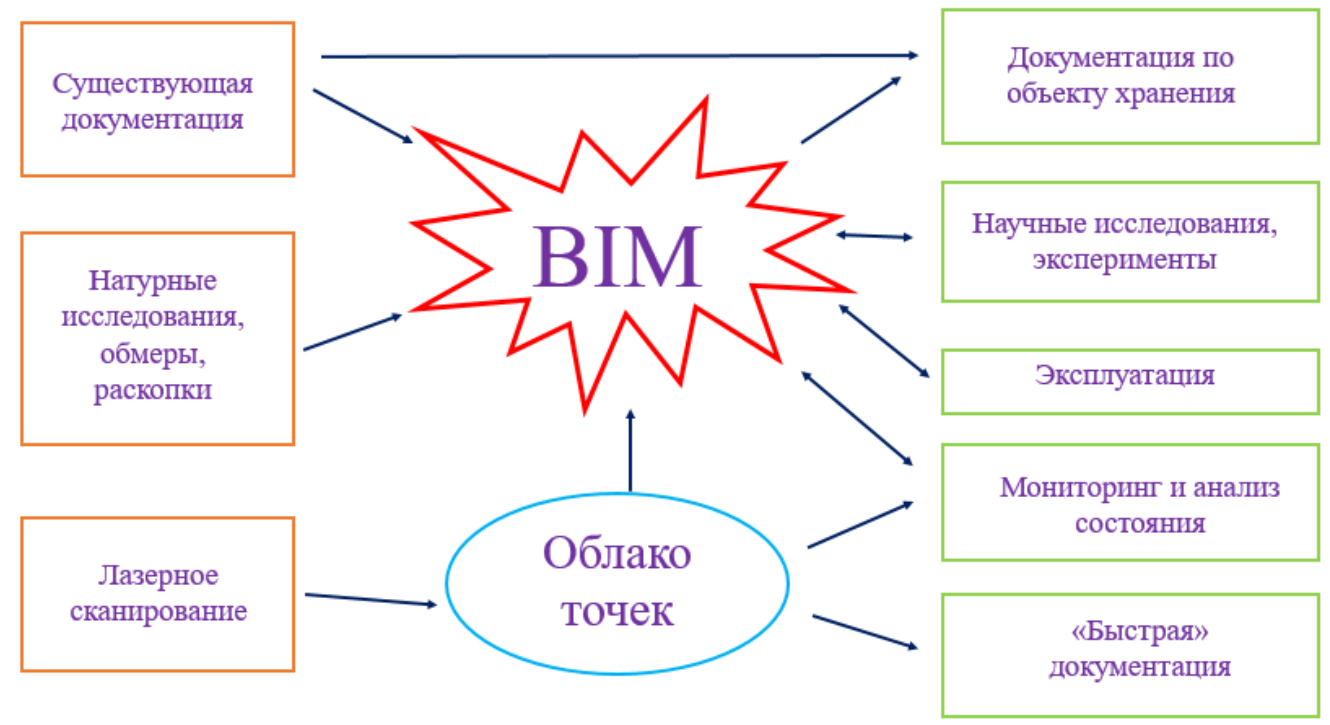

Рис. 2. Общая схема участия ВIM в работе с культурно-историческими объектами

При этом следует помнить, что в современных условиях наилучшей технологией получения реального облика здания является лазерное сканирование, которое зачастую становится неотъемлемой частью процесса информационного моделирования объекта культурно-исторического наследия. При этом также может применятся технология воздушного (Лидарного) лазерного сканирования с использованием БПЛА для получения цифровой модели рельефа.

При работе с такими объектами, особенно если они уже получили статус экспонатов или стали экспонатами музеев под открытым небом, возникает еще одна дополнительная задача-музеефикация, то есть детальное описание (вплоть до всех составляющих), с целью как научного исследования, так и поддержания стабильного состояния хранения.

В этом случае объектная модель должна строиться практически поэлементно с подробным описанием свойств каждого такого элемента. Более того, в дополнение к основным требованиям, предъявляемым к информационным моделям, для объектов истории и архитектуры появляется еще необходимость привязки к объекту целиком или его составным частям исторических документов и ресурсов. Такая добавочная информация может реализовываться либо через 
атрибуты элементов, либо через добавление в модель текстовых или 2D документов, либо подключением ссылок на интернет-порталы.

Создание информационных моделей памятников архитектуры предполагает сбор достоверной и достаточной информации и огромную аналитическую работу с архивными и проектными документами, техническими планами, старыми фото и кинодокументами. Кроме того, нужно владеть исчерпывающими данными о механических свойствах используемых строительных материалах, и в полной мере учитывать вышеперечисленные сведения при создании ВIM-модели. Результатом будет является создание электронных баз данных, содержащих библиотеки ВІМ-моделей объектов, отдельных архитектурных элементов и семейств. Полученные библиотеки информационных моделей могут быть применены для создания карт виртуальных городов или отдельных исторических кварталов с детальной проработкой зданий-памятников зодчества и их архитектурных элементов (рис. 3) Авторы данной статьи считают, что использование таких библиотек должно быть максимально открытым и доступным для проектно-реставрационной деятельности и научно-просветительских целях.

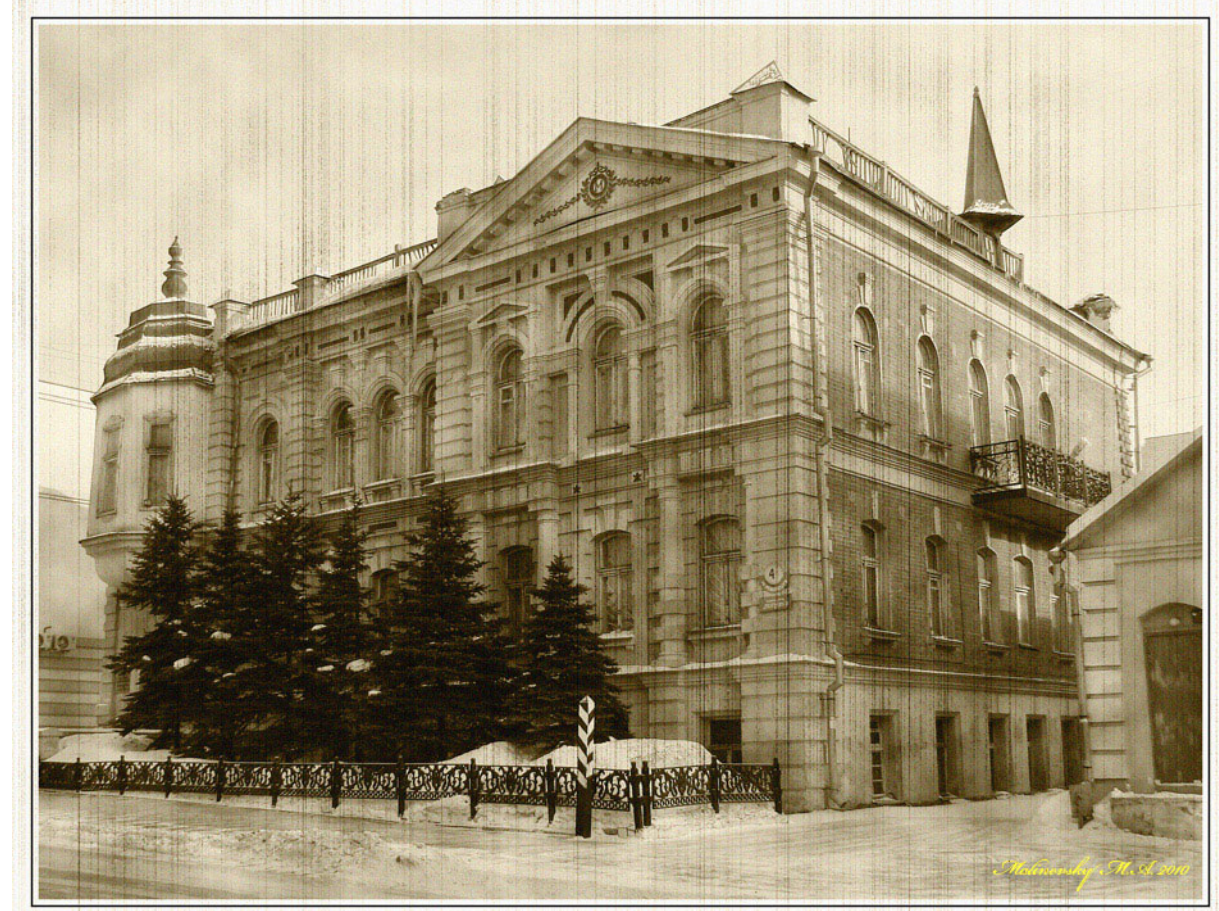

Рис. 3. Здание гостиницы «Метрополь» г.Новосибирск

В настоящее время на базе Санкт-Петербургского политехнического университета компанией «Vysotskiy Consulting» запущен пробный проект по созданию библиотеки трехмерных информационных моделей памятников архитектуры Нижнего Новгорода. В данном проекте принимают участие десятки команд различных ВУЗов России и ближнего зарубежья. Каждая из команд энтузиастов в области ВIМ-моделирования получает индивидуальное техническое задание на 
создание ВІМ-модели выбранного объекта, которое необходимо выполнить в установленные сроки в максимальном соответствии с требования, предъявляемым к информационным (BIM) моделям. Стоит отметить, что лучше прототипы объектов будут использованы при создании виртуальной карты города, создаваемой в рамках муниципального информационного интернет-портала.

По сложившейся терминологии информационная модель полное право считаться гибридной, объединяющей как фактические геометрические и физические характеристики объекта, так и оцифрованные документально-исторические свидетельства.

Благодаря этому ВIM становится уникальным технологическим мостиком между культурой прежних веков и нашей жизнью. Ранее такого сильного инструмента в руках архитекторов, рестовраторов и историков не было.

В новом проектировании хорошо зарекомендовала себя технология информационного моделирования зданий (BIM) на основе программного комплекса Autodesk Revit. Мы решили оценить возможность ее применения для реставрационного проектирования. А именно понять, насколько точно и просто средства Revit позволяют воссоздать облик памятника архитектуры, поскольку если информационная модель здания создана, то дальше вступают в силу все достоинства технологии BIM и реставрационное проектирование поднимается на качественно новый уровень.

Для исследования было выбрано здание кинотеатра «Металлист» эпохи конструктивизма, построенное в 1934 г., практически разрушенное в результате ряда нормативно-правовых коллизий, одним из которых являлось несвоевременной присвоение данному объекту статуса памятника культурно-исторического наследия, охраняемого государством (рис. 4). Выбор авторами данного объекта очевиден, и обусловлен высокой культурно-исторической значимостью первого звукового кинотеатра, и тем общественным резонансом, который был вызван попытками сноса здания.

В качестве программного средства применялся Autodesk Revit 2020.

Строился «Металлист» по проекту известного немецкого архитектора Эрнста Мая. Здание строилось как первый в городе звуковой кинотеатр, с уникальным сочетанием геометрических форм и функциональных элементов и является ярким примером архитектурного стиля, называемого конструктивизмом, распространенным в начале 30-х годов XX века. Осевая форма здания взята в виде цилиндра, который пронизан прямоугольными объемами. Оптимизм архитекторов первых десятилетий после революции дал волю фантазии и уверенности в том, что скоро можно будет смотреть на здания сверху. На плане западной части кинотеатра "Металлист" изображен объектив кинопроектора, из которого снимается проекционный луч, изображенный планом зрительного зала.

Рекреационная часть, соединяющая входной блок со зрительным залом, представляет собой одноэтажный объем сложной формы с просторным фойе и эстрадой.

Архитектурное, композиционное и декоративное решение фасадов является ярким примером, выполненным в стиле конструктивизма. Стены фасадов оштукатурены и выкрашены в белый цвет. 


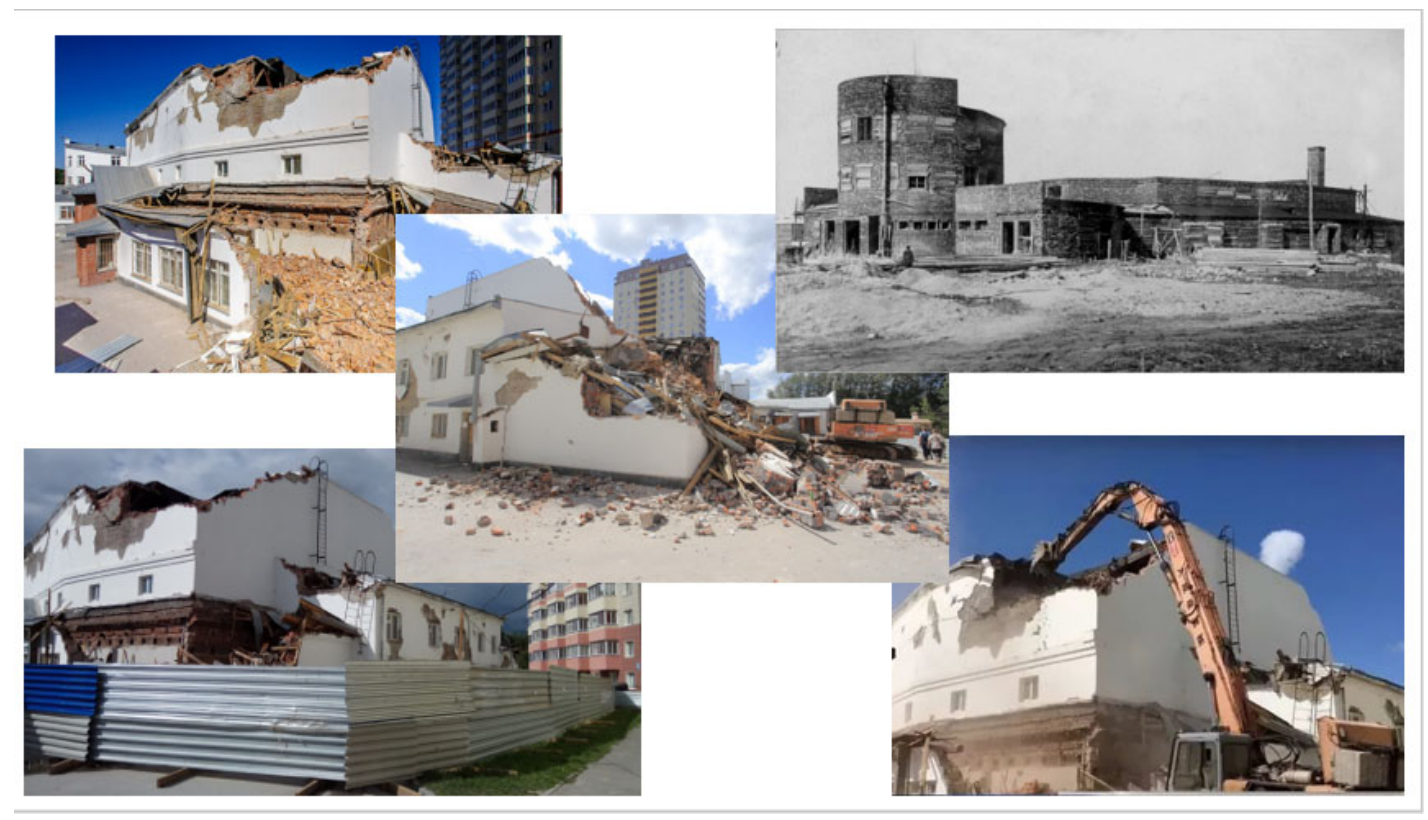

Рис. 4. Здание кинотеатра «Металлист» г. Новосибирск

Авторами статьи исследована возможность применения ВIM -технологии при разработке проекта реконструкции и планировки территории объекта культурно-исторического наследия. В рамках исследования была создана информационная модель кинотеатра «Металлист» (автор модели - Иванова Т.В) на основании существующей проектной документации (рис. 5).

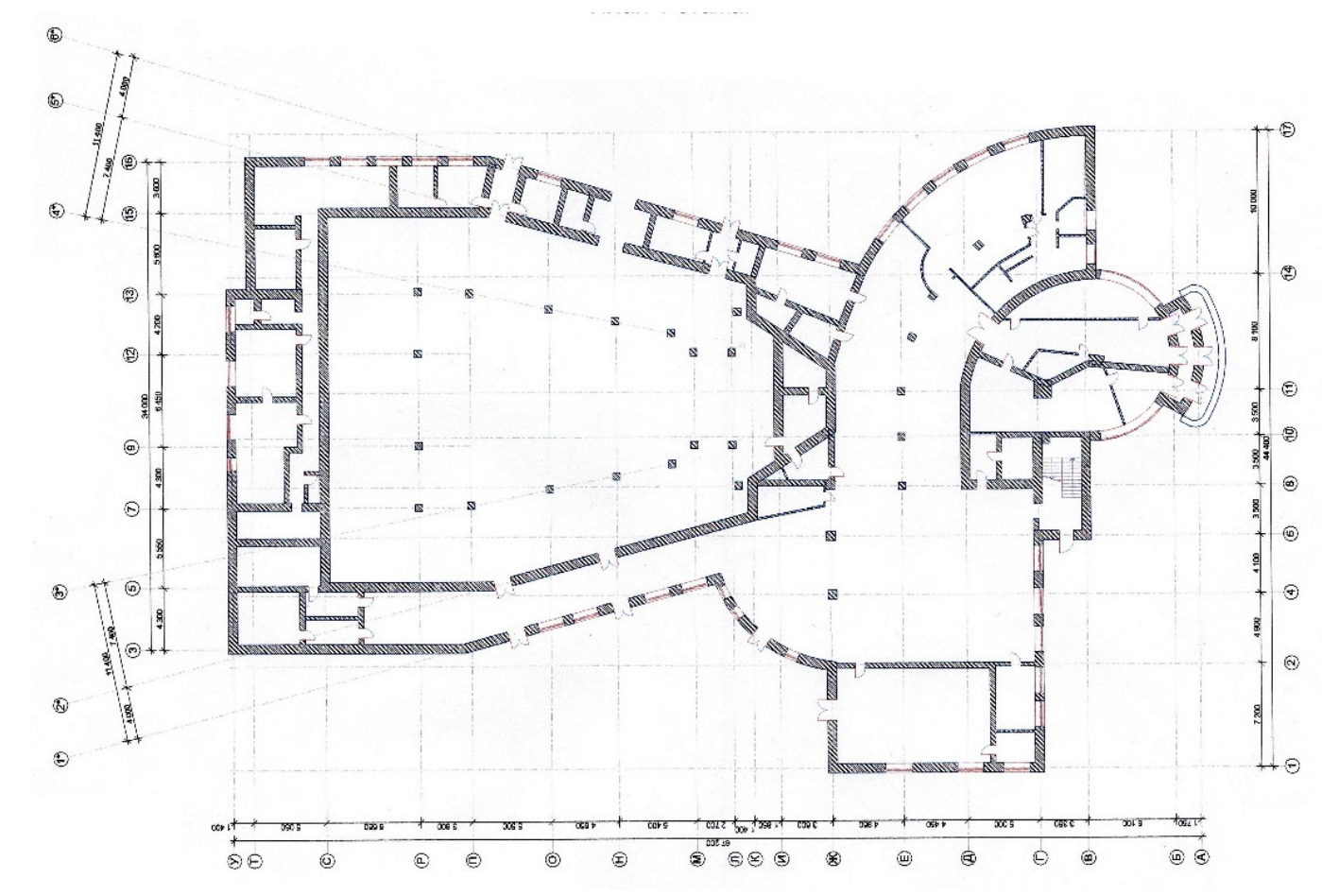

Рис. 5. План здания кинотеатра 
В качестве технического решения для создания ВIM-модели проектируемого объекта был выбран программный комплекс САПР Autodesk Revit. Комплекс Revit обеспечивает высокую точность выполняемых проектов и основан на новейшей технологии информационного моделирования объекта капитального строительства (ОКС). Также стоит отметить, что CAПР Revit позволяет создавать архитектурные формы, строительные конструкции и инженерные системы любой сложности $[9,10]$.

Результатом работы в САПР Revit является информационная модель здания школы, далее по тексту - объекта исследования, содержащая актуализированные сведения как о самом здании, включающие необходимую и достаточную информацию о материалах, входящих в структуру несущих и внутренних стен, перекрытий и отделки фасадов, так и о помещениях внутри него, которая представлена на рис. 6.

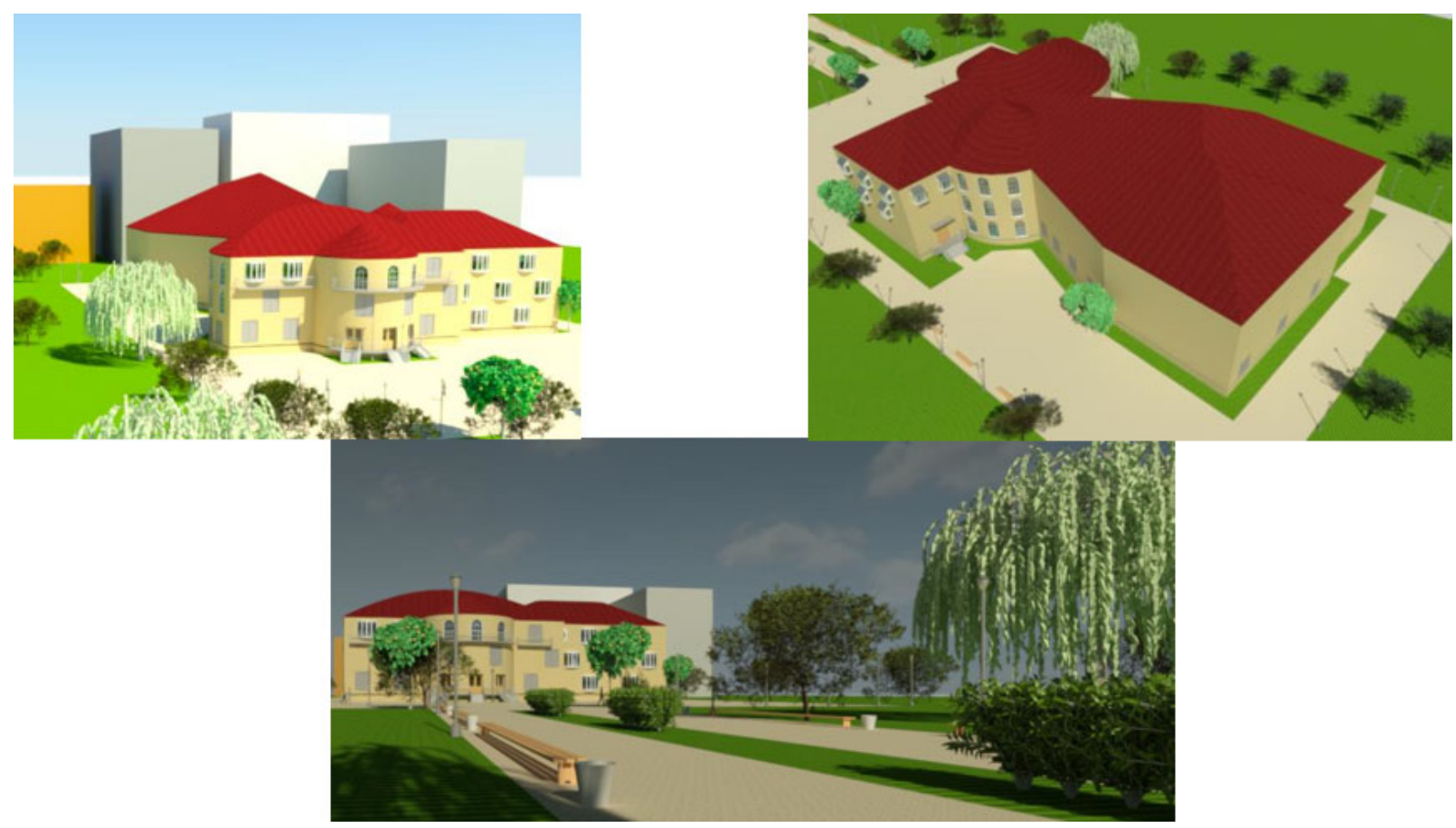

Рис. 6. Визуализация здания культурно-исторического наследия

Кроме того, объект исследования дополняют трехмерная модель окружающей территории с элементами планировки школьного двора и другие объекты капитального строительства и элементы антуража, расположенные на топоповерхности в строгом соответствии с планом окружающей территории

В конечном итоге можно с полной уверенностью сказать, что информационное моделирование зданий поднимает реставрационное проектирование на качественно новый уровень и может служить инновационным инструментом возвращения кинотеатру «Металлист» первоначального функционального назначения. И это выгодно всем участникам процесса градостроительства. Безусловно, город должен строиться и развиваться, но не за счет разрушения исторических 
памятников - необходимо заботиться о сохраненных объектах архитектурного наследия. Важно, чтобы преобладал комплексный подход к решению проблем реставрации, для чего ВІМ-технология открывает новые возможности.

\section{БИБЛИОГРАФИЧЕСКИЙ СПИСОК}

1. AUTODESK $®$ REVIT Building 8.0: Информационное моделирование объектов промышленного и гражданского строительства, 2014.

2. О Стратегии развития информационного общества в Российской Федерации на 2017 2030 годы : Указ Президента Российской Федерации от 09.05.2017 г. N 203 [Электронный ресурс]. - Доступ из информационно-правового портала «ГАРАНТ.РУ».

3. Об утверждении формы технического плана и требований к его подготовке, состава содержащихся в нем сведений, а также формы декларации об объекте недвижимости, требований к ее подготовке, состава содержащихся в ней сведений : Приказ Минэкономразвития России от 18.12.2015 N 953 [Электронный ресурс]. - Доступ из справ.- правовой системы «КонсультантПлюс».

4. Постановление от 16 февраля 2008 года №87 «О составе разделов проектной документации и требованиях к их содержанию».

5. Талапов В.В. Основы ВІМ: Введение в информационное моделирование зданий. М.:ДМК Пресс, 2011. -392с.

6. Купров А. В., Медведев П. П. Технология проектирования общественных зданий в среде Revit // Ресурсосберегающие технологии, материалы и конструкции. Региональная науч.-практ. конф. (Петрозаводск, 24 апреля 2015 г.). - Петрозаводск : Петропресс, 2016. C. 52-59.

7. Autodesk. Autodesk Revit Products. Retrieved from. https://www.autodesk.ru/products/ revit-family/overview.

8. Петров, М. П. Переход на BIM-технологии в проектировании на примере Autodesk Revit // Модернизация и научные исследования в транспортном комплексе : материалы конференции. - Пермь : Пермский национальный исследовательский политехнический университет, 2015. - Вып. 1. - С. 447-449.

9. Revit: просто о сложном [Электронный ресурс].- Режим доступа: http://easy4smart.blogspot.com/2014/04/revit-revit.html.- Загл. с экрана.

10. Autodesk Revit [Электронный ресурс].-Режим доступа: https://www.autodesk.ru/education/free-educational-software. - Загл. с экрана.

11. Талапов В.В. Основы ВІМ: Введение в информационное моделирование зданий. М.:ДМК Пресс, 2011. -392с.

12. Буравлева А.Ф., Клипина Н.А., Крутилова М.О. Внедрение ВІМ-технологий в процесс проектирования и строительства объектов недвижимости // Вестник научных конференций. - 2016. - № 10-3(14). - С. 36-39.

(C) T. В. Иванова, М. А. Малиновский, 2021 